\title{
INFLUENCE OF POINT DEFECTS ON THE EQUILIBRIUM CONCENTRATION OF INTERSTITIAL OXYGEN IN CRYSTALLINE SILICON
}

\author{
A. SARIKOV
}

PACS 64.75.Bc, 66.30.J-, 66.30.Lw, 81.30.Mh, 82.20.Wt (c) 2011

V.E. Lashkaryov Institute of Semiconductor Physics, Nat. Acad. of Sci. of Ukraine

(45, Nauky Ave., 03028 Kyiv, Ukraine; e-mail: sarikov@isp. kiev.ua)

The effect of excess point defects on the equilibrium concentration of interstitial oxygen for the system of interstitial oxygen $/ \mathrm{SiO}_{2}$ precipitates in crystalline $\mathrm{Si}$ is theoretically investigated. The expression for the equilibrium concentration of interstitial oxygen in Si modified by the excess point defects is derived. Excess vacancies in $\mathrm{Si}$ are found to decrease this concentration, while the excess $\mathrm{Si}$ self-interstitials have the opposite effect. The effects of different conditions for the point defect generation on the equilibrium in the system of interstitial oxygen $/ \mathrm{SiO}_{2}$ precipitates in crystalline $\mathrm{Si}$ are studied.

\section{Introduction}

Oxygen is the prevalent impurity in Czochralski grown crystalline Si material. It is incorporated interstitially in the silicon lattice up to the concentrations close to the solubility limit at the melting temperature. Upon cooling, a supersaturated solid solution of oxygen in silicon is formed. The supersaturated state of oxygen is released by the formation and the growth of precipitates of the $\mathrm{SiO}_{2}$ phase in Si bulk [1, 2]. These precipitates play a crucial role in the technology of crystalline Si wafers affecting their electrical and mechanical properties during the subsequent processing.

A number of investigations was devoted to the elaboration of theoretical models for the kinetics of oxygen precipitation in crystalline Si [3-5]. The formation of silicon oxide precipitates is affected by the excess point defects such as Si self-interstitials and vacancies participating in the precipitation process. The thermodynamic model of the influence of excess point defects on the nucleation of $\mathrm{SiO}_{2}$ precipitates in crystalline $\mathrm{Si}$ was proposed by Vanhellemont and Claeys [6]. They derived the expression for the critical radius of precipitate nuclei which uses the relative values of the concentrations of vacancies and $\mathrm{Si}$ self-interstitials in $\mathrm{Si}$ with respect to their solubility limits. The Vanhellemont-Claeys model shows that the critical radius of silicon oxide precipitates decreases with increase in the concentration of vacancies that provide the free volume to release the strain caused by the approximately two-time difference in the volumes of the $\mathrm{Si}$ and $\mathrm{SiO}_{2}$ phases. The stimulating vacancy effect on the oxygen precipitation in crystalline $\mathrm{Si}$ is used in the Magic Denude Zone technology [7] to promote the controlled formation of $\mathrm{SiO}_{2}$ precipitate ensembles in $\mathrm{Si}$ wafers. On the other hand, the critical radius of $\mathrm{SiO}_{2}$ precipitate nuclei increases, and the nucleation is hindered at the incorporation of the excess concentration of Si self-interstitials in crystalline Si.

Excess point defects in crystalline Si must also influence the concentration of interstitial oxygen in equilibrium with the precipitated $\mathrm{SiO}_{2}$ phase. This value has a significance of the minimum concentration of interstitial oxygen that can be achieved as a result of the thermal treatment of crystalline Si material. It determines, hence, the maximum possible precipitated Si concentration that should be increased, e.g. for the internal gettering purposes [8-10]. To our best knowledge, this question has not been addressed in detail previously. In the present paper, we make a theoretical study of the effect of supersaturations with vacancies and Si selfinterstitials on the equilibrium concentration of interstitial oxygen for the system of interstitial oxygen $/ \mathrm{SiO}_{2}$ precipitates (oxygen solubility limit) in crystalline $\mathrm{Si}$ as a function of the temperature of the Si processing and the conditions of the point defect generation. Our study is based on the Vanhellemon-Claeys nucleation model [6], as well as on the classical nucleation theory [11]. The obtained results are discussed in terms of experimentally observed modifications of the equilibrium concentration of interstitial oxygen in Si wafers subjected to treatments that lead to the point defect supersaturations.

\section{Theoretical Model}

According to the Vanhellemon-Claeys model [6], a change of the Gibbs free energy associated with the formation of a spherically shaped $\mathrm{SiO}_{2}$ precipitate with the 
number of oxygen atoms $j$ and the radius $R_{j}$ is expressed as follows:

$$
\begin{aligned}
& W_{j}=-j k_{\mathrm{B}} T \ln \left[\frac{C_{i}}{C_{i}^{\mathrm{eq}}}\left(\frac{V}{V_{\mathrm{eq}}}\right)^{\beta}\left(\frac{I}{I_{\mathrm{eq}}}\right)^{-\gamma}\right]+ \\
& +\left(36 \pi \Omega^{2}\right)^{1 / 3} \sigma j^{2 / 3}
\end{aligned}
$$

Here, $C_{i}$ and $C_{i}^{\text {eq }}$ are the concentration and the standard solubility limit of interstitial oxygen in crystalline Si, $V$ and $V_{\text {eq }}$ are the concentration and the solubility limit of vacancies, $I$ and $I_{\text {eq }}$ are the concentration and the solubility limit of Si self-interstitials, $\beta$ and $\gamma$ are the numbers of vacancies and Si self-interstitials absorbed and emitted per one oxygen atom incorporated into the precipitate, $\Omega$ is the volume per one oxygen atom in the $\mathrm{SiO}_{2}$ phase, $\sigma$ is the specific energy of the interface of $\mathrm{SiO}_{2}$ precipitate with the $\mathrm{Si}$ matrix, $k_{\mathrm{B}}$ is the Boltzmann constant, and $T$ is the temperature, respectively. In our analysis, the strain contribution to the Gibbs free energy associated with the formation of silicon oxide precipitates is not considered allowing the study of only the effect of excess point defects on the oxygen solubility. It is therefore assumed that all the strain is fully relaxed upon the vacancy absorption and/or the Si self-interstitial emission during the precipitate evolution. This assumption is plausible in definite cases in view of the experimental observation of the formation of unstrained $\mathrm{SiO}_{2}$ precipitates that have a structure consisting of 6-member rings of $\mathrm{SiO}_{4}$ tetrahedra [12].

The concentration of interstitial oxygen in a Si wafer changes as a result of the growth and the dissolution of $\mathrm{SiO}_{2}$ precipitates. The kinetics of this process in the case of large precipitates with size $j$, i.e. when the addition or subtraction of one oxygen atom has a vanishingly small effect on the precipitate radius, is described by the equation

$$
\frac{d C_{i}}{d t}=-\left(k_{j}^{+} C_{i}-k_{j}^{-}\right) N_{p},
$$

where $k_{j}^{+}$and $k_{j}^{-}$are the kinetic coefficients determining the rates of precipitate growth and dissolution, respectively, and $N_{p}$ is the precipitate concentration. The relation between the kinetic coefficients $k_{j}^{+}$and $k_{j}^{-}$is obtained from the classical nucleation theory in the following form [11]:

$$
k_{j}^{-}=k_{j}^{+} C_{i} \exp \left(\frac{\delta W\left(R_{j}\right)}{k_{\mathrm{B}} T}\right) \text {, }
$$

where $\delta W\left(R_{j}\right)$ is a change of the Gibbs free energy due to the addition of one oxygen atom to the precipitate with the number of oxygen atoms $j$ and the radius $R_{j}$. In view of formula (1), this expression acquires the following form:

$\delta W\left(R_{j}\right)=-k_{\mathrm{B}} T \ln \left[\frac{C_{i}}{C_{i}^{\mathrm{eq}}}\left(\frac{V}{V_{\mathrm{eq}}}\right)^{\beta}\left(\frac{I}{I_{\mathrm{eq}}}\right)^{-\gamma}\right]+\frac{2 \sigma \Omega}{R_{j}}$.

It is taken into account here that $\frac{4 \pi R_{j}^{3}}{3 \Omega}=j$ and $4 \pi \sigma\left(R_{j+1}^{2}-R_{j}^{2}\right) \approx 8 \pi \sigma R_{j} \frac{d R_{j}}{d j}=\frac{2 \sigma \Omega}{R_{j}}$, respectively.

Combining expressions (2) to (4), the following equation is obtained for the kinetics of change of the concentration of interstitial oxygen as a result of the growth and the dissolution of $\mathrm{SiO}_{2}$ precipitates of size $j$ :

$$
\begin{aligned}
& \frac{d C_{i}}{d t}=-k_{j}^{+} N_{p}\left[C_{i}-C_{i}^{\mathrm{eq}}\left(\frac{V}{V_{\mathrm{eq}}}\right)^{-\beta}\left(\frac{I}{I_{\mathrm{eq}}}\right)^{\gamma} \times\right. \\
& \left.\times \exp \left(\frac{2 \sigma \Omega}{R_{j} k_{\mathrm{B}} T}\right)\right] .
\end{aligned}
$$

The equilibrium state of the system of $\mathrm{SiO}_{2}$ precipitates with interstitial oxygen in crystalline $\mathrm{Si}$ corresponds to the zero value of the change of the latter concentration, $\frac{d C_{i}}{d t}=0$, which takes place at the value of $C_{i}$ equal to

$C_{i}=C_{i}^{e q}\left(\frac{V}{V_{\mathrm{eq}}}\right)^{-\beta}\left(\frac{I}{I_{\mathrm{eq}}}\right)^{\gamma} \exp \left(\frac{2 \sigma \Omega}{R_{j} k_{\mathrm{B}} T}\right)$.

The exponential term on the right-hand sides of Eq. (5) and expression (6) describes a modification of the equilibrium concentration of interstitial oxygen in the vicinity of precipitates in comparison to the bulk value due to the precipitate surface curvature (Gibbs-Thompson effect). Omitting this term, the following expression is obtained for the ratio of equilibrium concentrations of oxygen in crystalline Si bulk under supersaturations with point defects and without them:

$\frac{C_{i f}^{0}}{C_{i}^{e q}}=\left(\frac{V}{V_{\mathrm{eq}}}\right)^{-\beta}\left(\frac{I}{I_{\mathrm{eq}}}\right)^{\gamma}$

Expression (7) represents the key relation for the present study describing a modification of the concentration of interstitial oxygen in equilibrium with the $\mathrm{SiO}_{2}$ precipitates in a point defect-rich $\mathrm{Si}$ material with respect to the standard solubility limit. A detailed analysis of the influence of excess point defects on the equilibrium concentration of interstitial oxygen in $\mathrm{Si}$ is performed in the next section. 


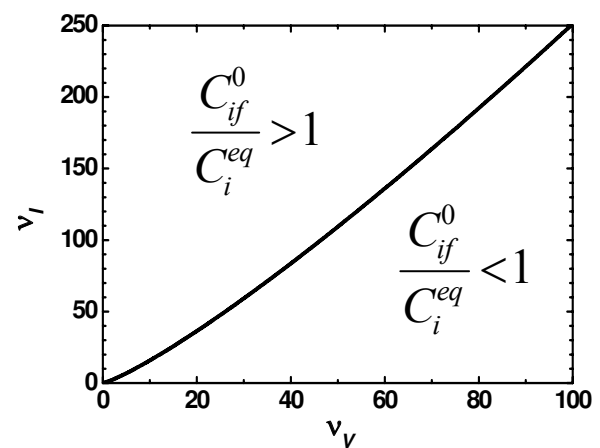

Fig. 1. Calculated dependence of the supersaturation with Si selfinterstitials upon the vacancy supersaturation that provide the unchanged value of the concentration of interstitial oxygen in crystalline $\mathrm{Si}$ in equilibrium with the precipitated $\mathrm{SiO}_{2}$ phase with respect to the solubility limit in the defect-free case. The regions of equilibrium interstitial oxygen concentrations below and above the standard solubility limit are also shown

\section{Results and Discussion}

As follows from expression (7), the solubility limit of interstitial oxygen in crystalline $\mathrm{Si}$ in the presence of excess point defects is principally determined by the term $\left(\frac{V}{V_{\mathrm{eq}}}\right)^{-\beta}\left(\frac{I}{I_{\mathrm{eq}}}\right)^{\gamma}$. Since both $\beta, \gamma>0$, the excess vacancies promote a decrease in the equilibrium concentration of oxygen dissolved in the interstitial state in $\mathrm{Si}$, and the excess Si self-interstitials have just the opposite effect. It is reported [13-15] that the full relief of the strain associated with the incorporation of one oxygen atom in $\mathrm{SiO}_{2}$ precipitate requires the absorption of $\sim$ 0.6 vacancies or, alternatively, the emission of one half Si self-interstitial, so that the values $\beta=0.6$ and $\gamma=$ 0.5 , respectively, are accepted.

We define $\nu_{V}=\frac{V}{V_{\mathrm{eq}}}$ and $\nu_{I}=\frac{I}{I_{\mathrm{eq}}}$ to be the supersaturations with vacancies and Si self-interstitials, respectively, and $f_{i}\left(\nu_{V}, \nu_{I}\right)=\frac{C_{i f}^{0}}{C_{i}^{\text {eq }}}=\nu_{V}^{-\beta} \nu_{I}^{\gamma}$ to be the ratio of the equilibrium concentrations of interstitial oxygen in the presence of excess point defects in $\mathrm{Si}$ and without them. The condition $f_{i}\left(\nu_{V}, \nu_{I}\right)=1$ determines those values of supersaturations with vacancies and $\mathrm{Si}$ self-interstitials at which the equilibrium concentration of interstitial oxygen in silicon remains unchanged with respect to that in the point defect-free case. This condition establishes the boundary between the regions of enhanced and reduced oxygen solubilities in crystalline Si. From the analysis of expression (7), the condition $f_{i}\left(\nu_{V}, \nu_{I}\right)=1$ is achieved at the relation between the values of supersaturations with $\mathrm{Si}$ self-interstitials and vacancies expressed by the function $\nu_{I}=\nu_{V}^{1.2}$. This function, as well as the regions of enhanced and reduced oxygen solubilities in crystalline $\mathrm{Si}$, is presented in Fig. 1. The effects of vacancy supersaturation are balanced at the supersaturations with Si self-interstitials higher by several times due to the higher power, to which $\nu_{V}$ is raised in the balance condition. The equal values of supersaturations with vacancies and Si self-interstitials lead to a decrease in the solubility limit of interstitial oxygen as $\nu_{V}^{-0.1}$ and, hence, to the enhancement of oxygen precipitation. In the following, we report on how different methods of excess point defect generation influence the concentration of interstitial oxygen in $\mathrm{Si}$ in equilibrium with the precipitated $\mathrm{SiO}_{2}$ phase.

One of the typical cases of the creation of an excess concentration of point defects is the generation of Frenkel pairs by, e.g., electrons, high-energy ions, or neutron irradiation of Si $[16,17]$. The point defects of both signs appear in equal concentrations during these processes, $V=I$. This ratio holds at $V \gg V_{\text {eq }}$ and $I \gg I_{\text {eq }}$. The function $f_{i}\left(\nu_{V}, \nu_{I}\right)$ expressed in terms of the vacancy concentration $V$ and the vacancy supersaturation $\nu_{V}$ acquires the following form in this case:

$f_{i}\left(\nu_{V}, \nu_{I}\right)=\left(\frac{V}{V_{\text {eq }}}\right)^{-0.6}\left(\frac{V}{I_{\text {eq }}}\right)^{0.5}=$

$=\left(\frac{V}{V_{\text {eq }}}\right)^{-0.1}\left(\frac{V_{\text {eq }}}{I_{\text {eq }}}\right)^{0.5}=\nu_{V}^{-0.1}\left(\frac{V_{\text {eq }}}{I_{\text {eq }}}\right)^{0.5}$.

Figure 2, $a$ shows the value of $f_{i}\left(\nu_{V}, \nu_{I}\right)$ as a function of the annealing temperature at different vacancy supersaturations under the condition of the equal concentrations of vacancies and Si self-interstitials. The data on the solubilities of vacancies and Si self-interstitials in crystalline Si are taken from [18], $V_{\text {eq }}=1.4 \times 10^{23} \exp \left(-\frac{2}{k T}\right) \mathrm{cm}^{-3}$ and $I_{\mathrm{eq}}=2.9 \times 10^{24} \exp \left(-\frac{3.18}{k T}\right) \mathrm{cm}^{-3}$, respectively. The values of $f_{i}\left(\nu_{V}, \nu_{I}\right)>1$, which demonstrates the stronger effect provided by the Si self-interstitials on the oxygen solubility limit during the Frenkel pair generation. Such an influence is resulted from the far lower solubility of Si self-interstitials in silicon compared to that of vacancies, which leads to their much higher supersaturations at equal defect concentrations. This is clearly demonstrated by the temperature dependence of $\frac{V_{\mathrm{eq}}}{I_{\mathrm{eq}}}$ presented in Fig. 2,b, which shows $\frac{V_{\mathrm{eq}}}{I_{\mathrm{eq}}} \gg 1$ for the entire region of temperatures used.

The analysis of expression (8) and Fig. 2, $a$ also reveals a decrease in the concentration of interstitial oxygen in $\mathrm{Si}$ in equilibrium with the precipitated $\mathrm{SiO}_{2}$ phase with increase in the vacancy supersaturation and the annealing temperature. In principle, there must be some 

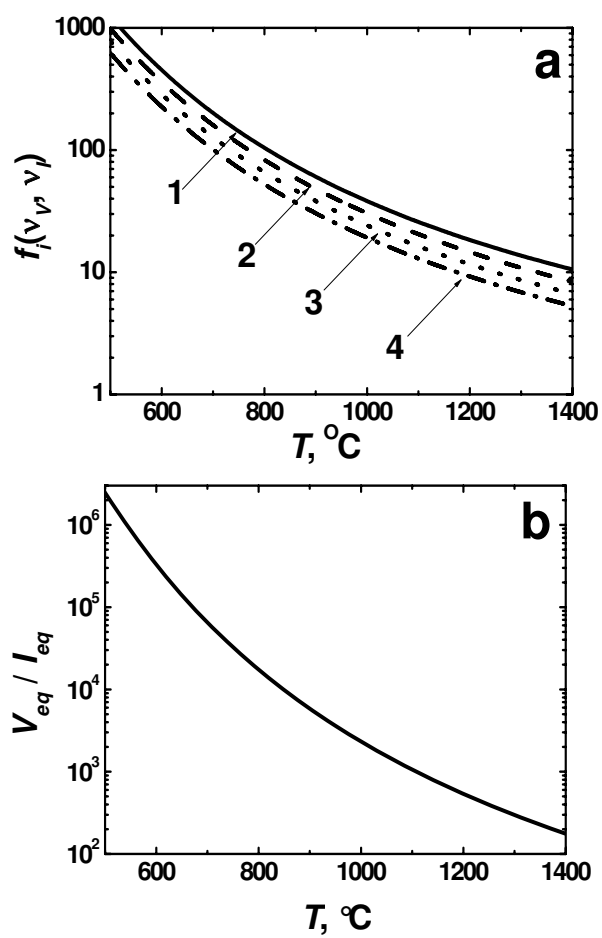

Fig. 2. $a-$ Calculated temperature dependences of the ratio of the concentrations of interstitial oxygen in crystalline $\mathrm{Si}$ in equilibrium with the precipitated $\mathrm{SiO}_{2}$ phase with and without excess point defects in the case of Frenkel pair generation for different vacancy supersaturations: $1-10,2-100,3-1000$, and $4-10000$. $b-$ Temperature dependence of the ratio of the solubility limits of vacancies and $\mathrm{Si}$ self-interstitials in crystalline $\mathrm{Si}$

critical vacancy supersaturation $\nu_{\text {cr }}$ at which the equilibrium concentration of interstitial oxygen is equal to its solubility limit in the defect-free case. The temperature dependence of $\nu_{\mathrm{cr}}$ is obtained from expression (8) setting $f_{i}\left(\nu_{V}, \nu_{I}\right)=1$ in the following form: $\nu_{\mathrm{cr}}=\left(\frac{V_{\mathrm{eq}}}{I_{\mathrm{eq}}}\right)^{5}$. However, the calculations by this formula, as well as the calculations of the respective critical vacancy concentrations, $V_{c r}=\nu_{\mathrm{cr}} V_{\mathrm{eq}}$, result in unreasonably high values (the critical vacancy concentration exceeds the atomic concentration of $\mathrm{Si}$ ), which is demonstrated by Fig. 3,a and $b$. This means that the Frenkel pair generation without $\mathrm{Si}$ self-interstitial drain leads in all the possible cases to an increase in the concentration of interstitial oxygen in equilibrium with the precipitated $\mathrm{SiO}_{2}$ phase and, hence, to the oxygen precipitation hindrance.

Another typical case is the quasiequilibrium distribution of the concentrations of point defects, which occurs when the local equilibrium between the point defects is established instantaneously as compared to any other process. Under these conditions, $V \times I=V_{\text {eq }} \times I_{\text {eq }}$, and
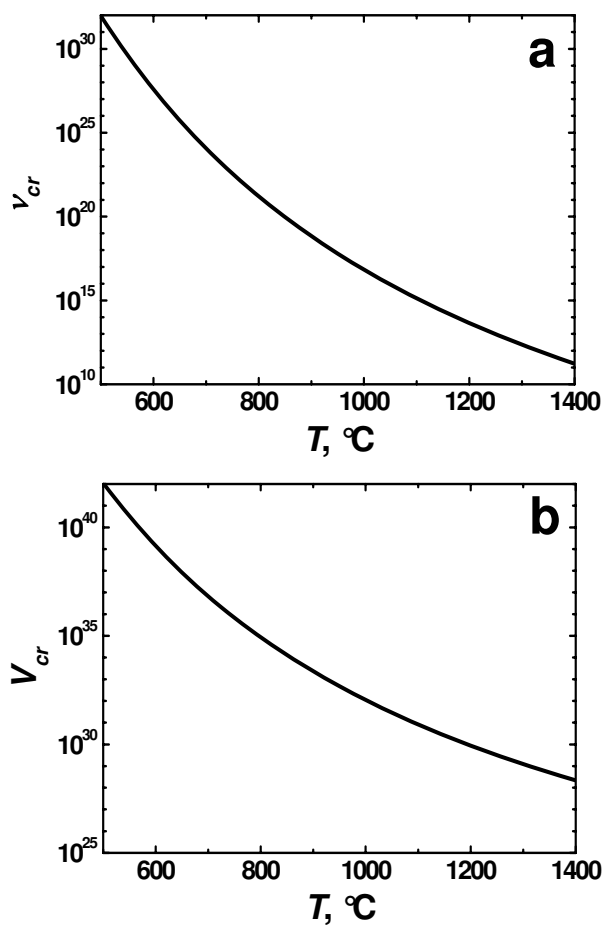

Fig. 3. Calculated temperature dependences of the critical supersaturation with vacancies $(a)$ and the critical vacancy concentration $(b)$ in the case of Frenkel pair generation in crystalline $\mathrm{Si}$

expression (7) in the terms of $\nu_{V}$ yields

$f_{i}\left(\nu_{V}, \nu_{I}\right)=\left(\frac{V}{V_{\text {eq }}}\right)^{-0.6}\left(\frac{V_{\text {eq }}}{V}\right)^{0.5}=\left(\frac{V}{V_{\text {eq }}}\right)^{-1.1}=\nu_{V}^{-1.1}$.

Expression (9) shows that the value $f_{i}\left(\nu_{V}, \nu_{I}\right)<1$, i.e. the equilibrium concentration of oxygen in point defectrich $\mathrm{Si}$ is smaller than that in the point defect-free $\mathrm{Si}$ when $\nu_{V}>1$ (vacancy-enriched $\mathrm{Si}$ ). We have $f_{i}\left(\nu_{V}\right.$, $\left.\nu_{I}\right)>1$, i.e. the oxygen equilibrium concentration in point defect-rich $\mathrm{Si}$ is higher than that in point defectfree $\mathrm{Si}$ at $\nu_{V}<1$ (self-interstitial-enriched $\mathrm{Si}$ ). Such situations can be realized by the predominant introduction of point defects of one sign in the Si material, e.g. by the high temperature rapid thermal annealing in the nitrogen (vacancies) or oxygen (interstitial Si atoms) atmosphere $[13,19,20]$. The microdefects of vacancy or interstitial nature formed in definite regions of the Si ingot pulled by the Czochralski method also enrich the Si bulk with point defects of a respective sign during subsequent Si wafer processing [21]. The concentration of vacancies can be also increased by applying the external pressure to the Si specimens [22]. The incorporated point defects reduce the steady-state concentration of 

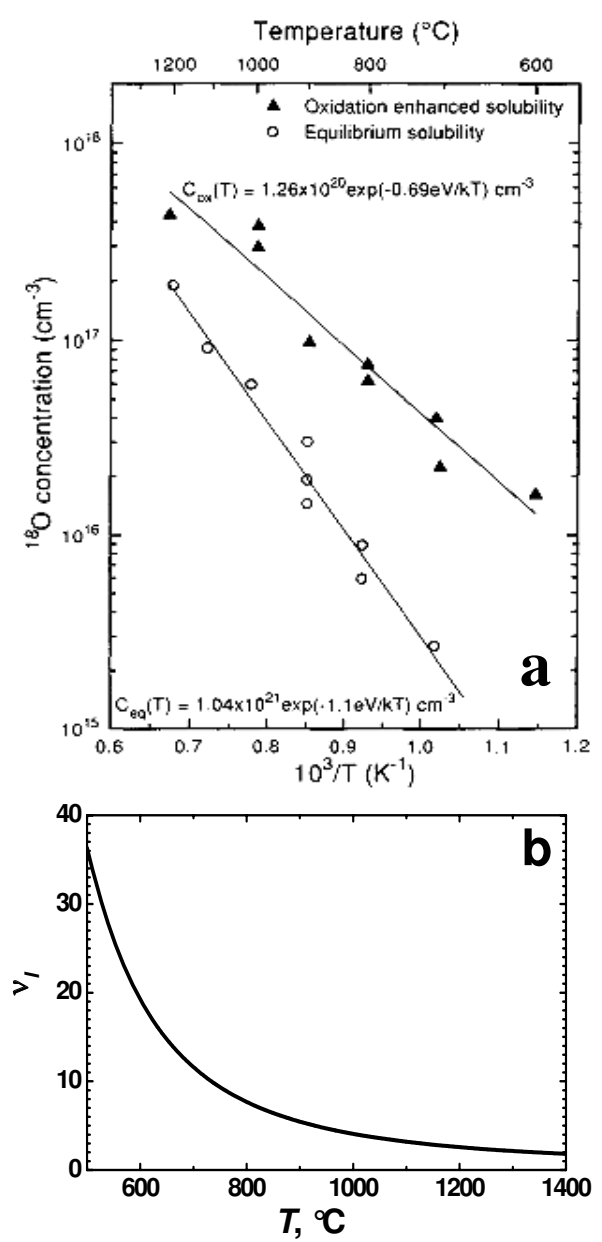

Fig. 4. $a$-Experimental temperature dependences of the oxygen solubility in Si during the oxidation and without it (reprinted from [23]). $b$ - Temperature dependence of the supersaturation with Si self-interstitials in Si calculated from the experimental data on the increase in the oxygen solubility resulted from the Si oxidation

the defects of opposite sign and enhance or hinder the oxygen precipitation in case of the vacancy or Si selfinterstitial enrichment, respectively.

The results of our investigations correlate with the available literature data. We are aware of several publications in which the modifications of the equilibrium concentration of interstitial oxygen in crystalline Si with excess point defects are reported. The enhanced solubility of interstitial oxygen in Si induced by the oxidation of the top Si layer by up to one order of magnitude was demonstrated by Mikkelsen [23]. The data on the oxygen solubilities in the case of Si surface oxidation and without it obtained in [23] are presented in Fig. 4,a. Although the author explains his results by an increase of the driving force for the oxygen dissolu- tion due to the establishment of a metastable equilibrium with the oxidizing ambient, we believe that the reason for the observed modification of the solubility of oxygen may be the influence of excess $\mathrm{Si}$ self-interstitials generated by the Si surface oxidation. Using the data in Fig. 4, $a$, the temperature dependence of the supersaturation with Si self-interstitials during the Si surface oxidation can be found from expression (9) in the following form: $\nu_{I}=0.146 \exp \left(\frac{0.37}{k T}\right)$. This dependence is shown in Fig. 4,b. According to it, the value of supersaturation with Si self-interstitials at the Si surface oxidation decreases with increase in the annealing temperature presumably due to the fast growth of the solubility of Si self-interstitials and lies in the range from several to several dozens times. A similar result on the oxidation-induced enhancement of the solubility of oxygen in crystalline Si was also obtained by Takano and Maki [24]. Schroer et al. used the oxidation-enhanced oxygen solubility in Si for the stimulation of the growth of a buried $\mathrm{SiO}_{2}$ layer in the $\mathrm{Si}$ wafer bulk [25].

The expression analogous to expression (7) but with the account of strain effects was derived by Ko et al. [5] for the quasiequilibrium concentration of interstitial oxygen at the interface of $\mathrm{SiO}_{2}$ precipitate with the $\mathrm{Si}$ surrounding. The authors, however, considered only a local equilibrium of $\mathrm{SiO}_{2}$ precipitate with oxygen dissolved in Si and made no references to this concentration as the minimum achievable bulk concentration of interstitial oxygen in Si and its dependence on the conditions for the formation of point defect supersaturations. Instead, we have established the conditions for the point defect generation to achieve the desired state of interstitial oxygen in crystalline $\mathrm{Si}$ and, hence, the required state of silicon oxide precipitate ensembles.

\section{Conclusion}

In this paper, the effect of excess point defects on the equilibrium concentration of interstitial oxygen for the system of interstitial oxygen $/ \mathrm{SiO}_{2}$ precipitates in crystalline $\mathrm{Si}$ is theoretically investigated. The expression for the equilibrium interstitial oxygen concentration modified due to the presence of excess point defects is derived. Excess vacancies in $\mathrm{Si}$ decrease this concentration due to the enhanced oxygen precipitation in the $\mathrm{SiO}_{2}$ phase. The presence of excess $\mathrm{Si}$ self-interstitials promotes the $\mathrm{SiO}_{2}$ precipitate dissolution and hence increases the equilibrium interstitial oxygen concentration.

The generation of Frenkel pairs in all the cases leads to the increase in the concentration of interstitial oxygen in $\mathrm{Si}$ in equilibrium with the $\mathrm{SiO}_{2}$ phase, which is explained 
by the easier supersaturation by Si self-interstitials due to their lower solubility comparing to that of vacancies. The supersaturation with one type of point defects in the quasiequilibrium regime affects the oxygen equilibrium concentration in a way pertinent to these defects. The modification of the conditions for the point defect generation during the thermal annealing of crystalline $\mathrm{Si}$ aimed at the oxygen precipitation in it enables a control over the precipitated state of oxygen and thus the characteristics of the internal getter in Si.

This work has been carried in the framework of the project $\Phi 28.7 / 051$ "Development of the scientific principles of the technology for the formation of dislocation free large diameter Si single crystals using the Czochralski method and the thermal treatments that control the state of oxygen atoms in the crystal lattice" of the Ministry of Education and Science of Ukraine, as well as the project 3.3-10 "Development and implementation of the technology for the formation of stress-free homogeneous Si ingots" of the National Academy of Sciences of Ukraine.

1. A. Borghesi, B. Pivac, A. Sassella, and A. Stella, J. Appl. Phys. 77, 4169 (1995).

2. V.M. Babich, N.I. Bletskan, and Ye.F. Venger, Oxygen in Silicon Single Crystals (Interpress, Kiev, 1997).

3. K.F. Kelton, R. Falster, D. Gambaro, M. Olmo, M. Cornara, and P.F. Wei, J. Appl. Phys. 85, 8097 (1999).

4. S. Isomae, J. Appl. Phys. 70, 4217 (1991).

5. B.G. Ko and K.D. Kwack, J. Appl. Phys. 85, 2100 (1999).

6. J. Vanhellemont and C. Clayes, J. Appl. Phys. 62, 3960 (1987).

7. R. Falster, V.V. Voronkov, and F. Quast, Phys. Stat. Solidi (b) 222, 219 (2000).

8. A.L. Endrös, Solid State Phenom. 32-33, 143 (1993).

9. J.P. Fillard, P. Gall, M. Gastagne, and J. Bonnafe, Solid State Phenom. 6-7, 403 (1989).

10. K. Moriya and T. Ogawa, J. Appl. Phys. 22, 207 (1983).

11. J.W. Christian, The Theory of Transformations in Metals and Alloys. Part I (Pergamon, Oxford, 1979).

12. V. Litovchenko, I. Lisovskyy, M. Voitovich, A. Sarikov, S. Zlobin, V. Kladko, and V. Machulin, Solid State Phenom. 156-158, 279 (2010).

13. R. Falster, M. Pagani, D. Gambaro, M. Cornara, M. Olmo, G. Ferrero, P. Pichler, and M. Jacob, Solid State Phenom. 57-58, 129 (1997).
14. J. Vanhellemont, Appl. Phys. Lett 68, 3413 (1996).

15. F.K. LeGoues, R. Rosenberg, T. Nguyen, F. Himpsei, and S. Meyerson, J. Appl. Phys. 65, 1724 (1989).

16. R.C. Newman, J. Phys.: Condens. Matter 12, R335 (2000).

17. J.L. Katz, J. Chem Phys. 55, 1414 (1971).

18. H. Bracht, N.A. Stolwijk, and H. Mehrer, Phys. Rev. B 52, 16542 (1995).

19. K. Tempelhoff and M. Van Sung, Phys. Stat. Solidi 72, 617 (1982).

20. M. Akatsuka, M. Okui, N. Morimoto, and K. Sueoka, Jpn. J. Appl. Phys. 40, 3055 (2001).

21. V.V. Voronkov and R. Falster, J. Cryst. Growth 204, 462 (1999).

22. J.Xu, D. Yang, C.Li, X. Ma, D. Que, and A. Misiuk, Mater. Sci. Eng. B 102, 84 (2003).

23. J.C. Mikkelsen, jr., Appl. Phys. Lett. 41, 871 (1982).

24. Y. Takano and M. Maki, in: Semiconductor Silicon 1973, edited by H.R.Huff and R.R.Burgess (Electrochem. Soc., Princeton, 1973), p. 469.

25. E. Schroer, S. Hopfe, J.-Y. Huh, and U. Gösele, Mater. Sci. Eng. B 36, 237 (1996).

Received 16.03.11

ВПЛИВ ТОЧКОВИХ ДЕФЕКТІВ НА РІВНОВАЖНУ

КОНЦЕНТРАЦЮЮ МІЖВУЗЛОВОГО КИСНЮ

У КРИСТАЛІЧНОМУ КРЕМНІЇ

\section{A. Саріков}

$\mathrm{P}$ е $з$ ю м е

У даній роботі теоретично досліджено вплив нерівноважних точкових дефектів на рівноважну концентрацію міжвузлового кисню для системи міжвузловий кисень-преципітати $\mathrm{SiO}_{2}$ у кристалічному кремнії. Отримано вираз для рівноважної концентрації міжвузлового кисню у кремнї, модифікованої присутністю нерівноважних точкових дефектів. Нерівноважні вакансії приводять до зменшення згаданої концентрації, тоді як нерівноважні міжвузлові атоми кремнію мають протилежний ефект. Вивчено вплив різних умов генерації точкових дефектів на рівноважну концентрацію міжвузлового кисню в системі міжвузловий кисень-преципітати $\mathrm{SiO}_{2}$ у кристалічному кремнії. 